\title{
Exploring the strategies for successfully building e-portfolios in medical schools
}

\author{
Su Jin Chae ${ }^{1}$ and Yong Won Lee ${ }^{1,2}$ \\ ${ }^{1}$ Department of Medical Education, Catholic Kwandong University College of Medicine, and ${ }^{2}$ Department of Internal \\ Medicine, International St. Mary's Hospital, Catholic Kwandong University College of Medicine, Incheon, Korea
}

Purpose: The purpose of this study is to examine the characteristics of resistance among medical students toward e-portfolios and find the strategies for them to successfully prepare e-portfolios.

Methods: Participants were a group of 258 medical students. The questionnaire comprised 13 items developed based on the innovation resistance theory. The data were analyzed using descriptive analysis and Spearman's correlation analysis using PASW SPSS version 18.0 (SPSS Inc., Chicago, USA).

Results: Students perceived that e-portfolios have a high degree of relative advantage, trialability, and complexity as their innovation resistance characteristics. Regarding perceived risk, they did not want others to see their information, but they had a high degree of demand for communication with their professors.

Conclusion: The successful use of portfolios can serve as a tool for student management and assessment that can reflect their introspection, personal development, and academic performance. This study proposed the strategies to promote the use of e-portfolios by strengthening education on the need for them, specific feedback of instructors, and students' autonomy.

Key Words: E-portfolio, Medical, Outcome assessment, Undergraduate

\section{Introduction}

Portfolios are used as an alternative and objective tool for student assessment in competency-based education [1,2]. E-portfolios are being adopted by medical schools in Korea to compensate for the deficiencies of paperbased ones when assessing the attitudes required by doctors in students, such as empathy, communication, leadership, and introspective abilities. However, even though schools are developing a system for e-portfolios and encouraging students to use them, medical students seem unsatisfied [3]. For e-portfolios to be successfully established as an assessment tool in medical schools, it is necessary to consider students' complaints about them, which reflect the reasons for their resistance.

A portfolio is a collection of one's activities and outputs [4]. It also reflects learning performance, contents, and methods, continuous growth records, selfreflection, various learning activities, and continuous feedback, among others. The fact that the portfolio serves as an assessment tool similar to a test that evaluates knowledge, may trigger resistance among medical students. Implementing a new assessment
Received: April 1, 2021 • Revised: April 6, 2021 • Accepted: April 6, 2021 Corresponding Author: Yong Won Lee (https://orcid.org/0000-0002-6174-3479) Department of Internal Medicine, International St. Mary's Hospital, Catholic Kwandong University College of Medicine, 25 Simgok-ro 100beon-gil, Seo-gu, Incheon 22711, Korea Tel: +82.32.290.2821 Fax: +82.32.290.3879 email: ywlee@cku.ac.kr
Korean J Med Educ 2021 Jun; 33(2): 133-137

https://doi.org/10.3946/kjme.2021.188

eISSN: 2005-7288

(C) The Korean Society of Medical Education. All rights reserved. This is an open-access article distributed under the terms of the Creative Commons Attribution Non-Commercial License (http:// creativecommons.org/licenses/by-nc/3.0/), which permits unrestricted non-commercial use, distribution, and reproduction in any medium, provided the original work is properly cited. 
method or program in the educational setting is a complicated process that requires a great deal of time and effort. Furthermore, if the new attempt is innovative and requires physical and mental effort, there is bound to be even greater resistance [5].

The purpose of this study is to determine the characteristics of resistance medical students have toward e-portfolios based on innovation resistance theory of Ram [6]. The research aims to explore an action plan for successfully building e-portfolios.

\section{Methods}

The College of Medicine at Catholic Kwandong University (CKU) has developed an e-portfolio platform and used it as a student management system since 2018. Medical students use the CKU e-portfolio to create, implement, and assess their plans throughout their 6 years of college. It is designed for them to not only achieve their goals, but also assess their achievements before graduation. It comprises four domains: self-development, academic activities, extracurricular activities, and learning performance assessment.

A survey was conducted for 2 weeks in December
2019. The subjects were 280 students in the 2 nd through 6th year of study who experienced using CKU $\mathrm{e}^{-}$-portfolios for at least a year. After excluding those who did not fully respond to or agree to participate in the survey, a total of 258 students were included in the sample for data analysis.

The questionnaire comprised a total of 13 items rated on a 5-point scale, which was reviewed by one specialist in medical education. The survey data were analyzed using descriptive statistics and Spearman's correlation using PASW SPSS ver. 18.0 (SPSS Inc., Chicago, USA). Cronbach's $\alpha$ reliability of the items was 0.91 , which was relatively high. Out of 10 characteristics of innovation resistance suggested by Ram [5], five characteristics with a high degree of explanatory power in medical schools, such as relative advantage, compatibility, complexity, trialability, and perceived risk, were selected. The survey questions are shown in Table 1

This study was approved by the Institutional Review Board of the the International St. Mary's Hospital, Catholic Kwandong University College of Medicine (IRB approval no., IS19QISI0026).

Table 1. Characteristics of Innovation Resistance

\begin{tabular}{ll}
\hline \multicolumn{1}{c}{ Characteristic } & \multicolumn{1}{c}{ Items } \\
\hline Relative advantage & 1. It helped me understand my strengths and weaknesses. \\
& 2. I could reflect on my learning plans and activities. \\
3. It helped me explore my career path. \\
4. The portfolio style is compatible with the way I study. \\
5. The portfolio is compatible with my intention to record and introspect. \\
6. The portfolio is compatible with my need to communicate with the professors. \\
7. Filling out the portfolio seems difficult and complicated. \\
8. A separate learning session is needed for filling out the portfolio. \\
9. I can fill out the portfolio on my own. \\
10. It was convenient to use the online system. \\
11. Filling out the portfolio may be a waste of time. \\
12. I am worried that my academic advisor may give negative comments. \\
13. I do not want others to see my information.
\end{tabular}




\section{Results}

The results are presented in Table 2. The students had a positive perception in terms of relative advantage and trialability. Their responses indicated that $\mathrm{e}-$ portfolios help them better understand themselves $(2.83 \pm 1.01)$ and explore their career paths $(2.77 \pm 1.09)$. The fact that it is available online is also convenient for them $(3.22$ $\pm 1.07)$. The complexity score was also high (3.61 \pm 1.04$)$, suggesting that the students felt the portfolio was difficult and complicated to fill out. They also indicated that a separate learning session is needed for them to understand how to fill out the portfolio $(2.86 \pm 1.11)$.

The correlation among the characteristics showed that there were mostly positive correlations between relative advantage and other characteristics, whereas there were negative correlations between complexity and perceived risk. Students with negative correlations did not want others to see their information ( $r=-0.157)$, thought that the portfolio was not compatible with the way they study $(r=-0.148)$, and felt that filling it out was a waste of time $(\mathrm{r}=-0.356)$. For items showing a positive correlation with risk and complexity, students were worried that their academic advisor would give negative comments. Their responses also suggested that they wanted to com- $^{-}$ municate with their professors through the portfolio $(r=0.256)$.

\section{Discussion}

The present study explored the strategies in which the quality of e-portfolio can be improved and how the system can be successfully implemented based on the innovation resistance theory. Portfolios serve as records that can develop the capabilities of students through

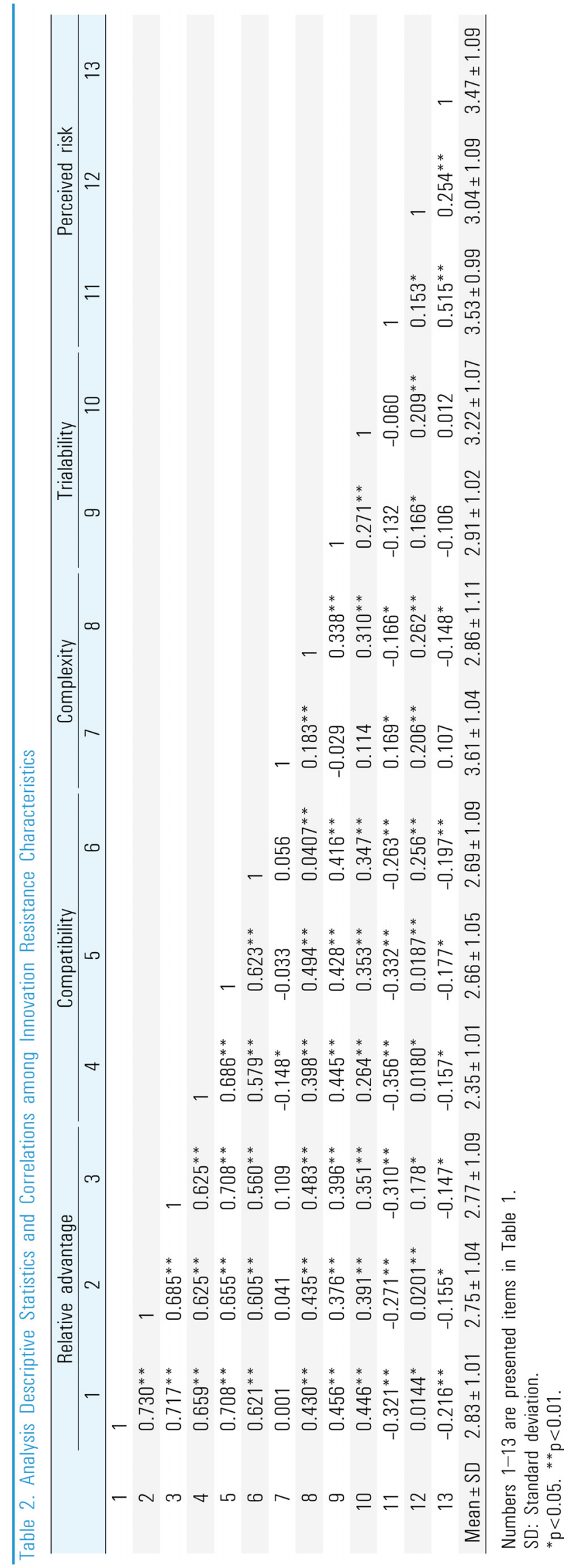


time and document the growth of the learner's expertise through data collection [7]. These are the reasons why they are actively used to assess students' attitudes in medical schools along with reflective journals, essays, self-rating, learning goal achievements, and professionalism. However, despite these intentions, students consider it a burden to fill out their portfolios due to the nature of medical school or excessive academic stress. In some cases, they tend to fill them out as a mere formality or to show negative responses. The results of this study showed that students with high scores in relative advantage considered portfolios as a tool to stimulate reflective thinking and communicate with professors. On the other hand, those with low scores in relative advantage, compatibility, and trialability tended to think that filling out the portfolio was a waste of time. Based on these results, the following can be suggested the strategies to promote the use of e-portfolios:

First, guideline on portfolios is needed [8]. Students may show resistance to portfolios if they are given as an assignment without sufficient explanation as to their significance and educational values. As shown in the results, even students who do not consider portfolios as difficult or complicated responded that guidelines on the importance and value of filling out portfolios must be provided through sufficient education.

Second, specific and detailed feedback is needed from instructors [9]. It is important for students to feel that they are growing personally through the process of having the instructor review the outcomes of their portfolios and provide feedback. They fill out their portfolios without actually knowing whether they are meeting its purpose. Thus, the reason for building a portfolio is lost in the process, and the portfolios are merely reduced to an assignment they must complete.

Third, students' autonomy is essential [8]. Students who think that filling out a portfolio is difficult and complicated are likely to show stronger resistance, and thus cannot successfully build their portfolios. A portfolio can be a measure of the diverse experiences individual students may gain in the rigid curriculum of medical school where they have to study around the clock. Therefore, there must be various ways of expressing their activities or experiences. By establishing an open structure and providing autonomy for students to develop their own portfolios in various ways with individuality and originality, it will be possible for them to build a more meaningful portfolio.

The limitation of this study is that it was only conducted using limited data from one medical school; thus, the results cannot be generalized. However, this study discovered that building and operating a successful e-portfolio is not only a good student management tool, but also a student assessment tool that can encompass student introspection, personal growth, and academic assessment.

ORCID:

Su Jin Chae: https://orcid.org/0000-0003-3060-8933;

Yong Won Lee: https://orcid.org/0000-0002-6174-3479

Acknowledgements: None.

Funding: None.

Conflicts of interest: No potential conflict of interest relevant to this article was reported.

Author contributions: Conception or design of the work, CSJ, LYW; data collection, data analysis and interpretation, drafting the article, CSH; critical revision of the article, and final approval of the version to be published: LYW. 


\section{References}

1. Carraccio C, Englander R. Evaluating competence using a portfolio: a literature review and web-based application to the ACGME competencies. Teach Learn Med. 2004;16(4):381-387.

2. Driessen E, van Tartwijk J, Vermunt JD, van der Vleuten CP. Use of portfolios in early undergraduate medical training. Med Teach. 2003;25(1):18-23.

3. Yoo DM, Han JJ, Eo EK. A survey of student satisfaction with a portfolio process and assessment. Korean Med Educ Rev. 2014;16(1):42-49.

4. Driessen E, van Tartwijk J, van der Vleuten C, Wass V. Portfolios in medical education: why do they meet with mixed success?: a systematic review. Med Educ. 2007; 4l(12):1224-1233.
5. Yu J, Chae S. The mediating effect of resilience on the relationship between the academic burnout and psychological well-being of medical students. Korean J Med Educ. 2020;32(1):13-21.

6. Ram S. A model of innovation resistance. Adv Consum Res. 1987;14:208-212.

7. Tochel C, Haig A, Hesketh A, et al. The effectiveness of portfolios for post-graduate assessment and education: BEME Guide No 12. Med Teach. 2009;31(4):299-318.

8. Chertoff J, Wright A, Novak M, et al. Status of portfolios in undergraduate medical education in the LCME accredited US medical school. Med Teach. 2016;38(9): 886-896.

9. Westberg J, Jason H. Fostering reflection and providing feedback: helping others learn from experience. New York, USA: Springer Publishing Company Inc.; 2001. 